Muhammet Yurdakul

Bayburt University, myurdakuldbayburt.edu.tr, Bayburt-Turkey Şevket Ates

Karadeniz Technical University, sates@ktu.edu.tr, Trabzon- Turkey

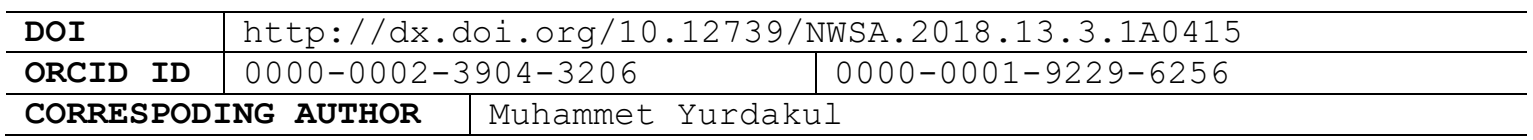

\title{
EFFECTIVENESS OF WAVE PASSAGE EFFECT OF SEISMIC ISOLATED AND NONISOLATED BRIDGES UNDER SPATIALLY VARYING GROUND MOTION
}

\section{ABSTRACT}

In this study, stochastic analyses of isolated and nonisolated highway bridges under spatially varying ground motion are performed. The bridge is isolated with triple concave friction pendulum (TCFP) bearing. The selected bridge is assumed to be constructed on homogeneous soft soil. Incoherency effects are neglected and wave passage effect is taken into account in the stochastic analyses. The bridge model subjected to spatially varying earthquake ground motions in the horizontal direction. The horizontal input is assumed to travel across the bridge from left to right side with finite velocities of $100 \mathrm{~m} / \mathrm{s}, 200 \mathrm{~m} / \mathrm{s}$ and $400 \mathrm{~m} / \mathrm{s}$. The means of the maximum responses of displacement and internal forces of bridge deck are investigated. The results of these stochastic analyses are also compared with the results of infinite velocity. Analysis results show that using TCFP bearing on Highway Bridge reduces means of maximum values of total axial force, shear force and bending moment of bridge deck by 89\%, 86\% and 96\%, respectively. In generally, low speed is more effective than high speed at the means of the maximum responses of internal forces of bridge deck. The finite velocity is the most effective at means of the maximum responses of horizontal displacement of bridge deck.

Anahtar Kelimeler: Stochastic Analysis, Seismic Isolation, Sliding Isolation System, Triple Friction Pendulum Bearing, Wave Passage Effect

\section{INTRODUCTION}

The highway bridges are important engineering structures for transportation, so these types of structures are constructed to withstand severe earthquake ground motions. Thus, using stochastic approach considering incoherence, wave-passage and site-response effect along with seismic isolation system should be used on designing long span structures as highway bridges. Triple concave friction pendulum (TCFP) bearing used in this study based on one of the most effective sliding isolation system, namely friction pendulum system is proposed by Zayas et al. [1]. TCFP bearing system consists of two facing concave stainless steel surfaces and an articulated slider is separately placed between the two spherical stainless steel surfaces. Namely, in the later system motions occur in three sliding surfaces, so the system is named as triple. The principles of operation and force-displacement relationship of the TCFP bearing are developed by Fenz [2]. The TCFP bearing system is more effective than other sliding systems [3 and 7]. Dynamic responses analysis for long span How to Cite:

Yurdakul, M. and Ateş, Ş., (2018). Effectiveness of Wave Passage Effect of Seismic Isolated and Nonisolated Bridges Under Spatially Varying Ground Motion, Engineering Sciences (NWSAENS), 13(3): 229-246, DOI: 10.12739/NWSA.2018.13.3.1A0415. 
nonisolated and isolated bridge subjected to spatially varying ground motions were investigated by Harichandran and Wang [8]. Ates et al. [9] compared stochastic response of nonisolated and isolated cablestayed bridge with double concave friction pendulum (DCFP) bearing subjected to spatially varying ground motion. Analyses results show that spatially varying ground motion should be taken account in the isolated bridge. Avanoglu and soyluk [10] were carried out a study investigated dynamic characteristic of cable bridge subjected to spatially varying ground motion including wave passage effect and incoherency effect.

Li et al. [11] performed an experimental study to evaluate the influence of spatially varying ground motions on the pounding behaviour of the adjacent bridge segments. Analysis results were showed that spatially varying ground motions increase the relative displacement of adjacent bridge girders and pounding forces. Jia et al. [12] studied on a theoretical non stationary stochastic analysis scheme for seismic analysis of long-span structures under tri directional spatially varying ground motions. A high-pier railway bridge under spatially varying ground motion including local site effect was selected to nonstationary stochastic analysis. Bedon and Morassib [13] carried out dynamic characterization of isolated Dogna bridge using harmonic vibration tests and finite element analysis. They developed a theoretical procedure to estimate the elastic stiffness of the isolators. Analysis results showed that theoretical procedure propounded was acceptable. Bo et al. [14] executed a study investigated responses of multi and large span bridge under multi support random excitations. In the analysis results showed that multi support excitations should be considered in long span structures. Fallahian et al. [15] examined the responses of torsionally coupling base-isolated structure with TCFP bearing subjected to near field ground motions in the nonlinear dynamic analyses. Also the responses of isolated structure with TCFP bearing were compared with same structure using friction pendulum system (FPS) and DCFP bearing. Analysis results indicate that using TFP bearing more efficient than other types of friction bearings.

sayed et al. [16] investigated effects of the spatial variation of ground motions on the seismic responses of a seismic isolated nuclear power plants. The seismic responses of the seismic isolated structures were analyzed under the uniform and spatial varying excitation of El Centro ground motion. Analysis results indicated that considering the spatial variation of ground motions have substantial influences on behaviour of isolator device. Apaydin et al. [17] investigated responses of Fatih Sultan Mehmet Bridge under spatially varying ground motions. Spatially varying ground motions were generated using finite-fault technique in three directions for each support. Results from obtained analysis using spatially varying ground motions and uniform ground motions were compared. The study indicated that spatially varying ground motions should be considered in analysis of large structure as highway bridges. Adanur et al. [18] carried out multi support excitations analyses of Bosphorus Suspension Bridge for various random vibration methods. The spatial variability of ground motions was taken into account with the incoherence, wave-passage and site-response effects. Analysis results showed that the structural responses for each random vibration analysis depend on the intensity and frequency contents of power spectral density functions.

\section{RESEARCH SIGNIFICANCE} bridges isolated with different of cable-stayed and highway sliding systems have been 
investigated, TCFP bearing system is not taken into account so far. The aim of this study is to investigation the wave-passage effect on highway bridge under spatially varying earthquake ground motions. Also the effectiveness of the TCFP bearing system used will be investigated depending on the speed. In accordance with this purpose, the horizontal input is assumed to travel across the bridge from left to right side. The finite velocities are selected as $100 \mathrm{~m} / \mathrm{s}, 200 \mathrm{~m} / \mathrm{s}$ and $400 \mathrm{~m} / \mathrm{s}$ for soft soil condition in The Turkish Seismic Code DBYBHY2007 [19]. The means of the maximum responses of displacement and internal forces of bridge deck are investigated. The results of these stochastic analyses are also compared with the results of finite velocity.

\section{EXPERIMENTAL METHOD-PROCESS}

TCFP bearing derived from single concave friction pendulum (SCFP) bearing was proposed by Zayas et al., [1]. Differences between TCFP bearing and other friction pendulum bearings are multiple changes in stiffness and strength with increasing amplitude of displacement [20]. The TCFP bearing used in this study shown in Figure 1. This system is consisted of two facing concave stainless steel surfaces coated with Teflon separated by a placed slider assembly. In the Figure $1, R_{i}$ is the radius of curvature of surface $i, h_{i}$ is the radial distance between the pivot point and surface $i, \mu_{i}$ is the coefficient of friction at the sliding surface $i$ and $d_{i}$ is the displacement capacity of the surface $i$. Outer concave plates have effective radii $\mathrm{R}_{\mathrm{effl}}=\mathrm{R}_{1}-\mathrm{h}_{1}$ and $\mathrm{R}_{\mathrm{eff} 4}=\mathrm{R}_{4}-\mathrm{h}_{4}$. The articulated slider assembly consists of two concave plates separated by a rigid slider. While the innermost slider is rigid, the assembly as a whole has the capability to rotate to accommodate differential rotations of the top and bottom plates. The friction coefficients on these concave plates are $\mu 1$ and $\mu 4$. The inner concave plates have effective radii $R_{\text {eff } 2}=R_{2}-h_{2}$ and $R_{\text {eff } 3}=R_{3}-h_{3}$. The friction coefficients on these concave plates are $\mu_{2}$ and $\mu_{3}$. In case of economic benefit is taken into account, there is no significant differences between the SCFP and the DCFP bearings. The TCFP bearing is cost effective as per bearing size and displacement capacity.

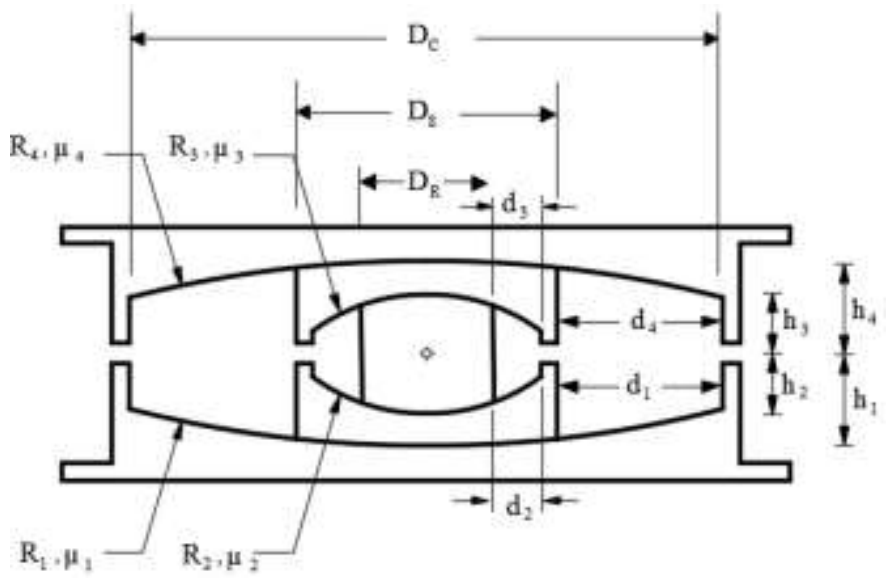

Figure 1. The cross-section and parameters of the TCFP bearing

In this study, a sample design suggestion is used to determined parameters of TCFP bearing system [21]. The all parameters are shown in Figure 1 was studied to determine. The TCFP bearing has 16 parameters. 12 parameters related to geometry. The others are composed of the friction coefficient. In generally, diameter of concave plates, $R_{1}$ and $R_{2}$, are equal to $2235 \mathrm{~mm}$ and $3048 \mathrm{~mm}$ respectively. However, 
diameters of these surfaces are selected as $3092 \mathrm{~mm}$ because earthquake record is used analysis and piers are supported on different soil conditions. When the diameter is selected bigger value, re-centering force is not enough for a Design Basis Earthquake (DBE). This situation is checked by Equation (1).

$$
\mathrm{T} \leq 28\left(\frac{0.05}{\mu}\right)^{\frac{1}{4}}\left(\frac{\mathrm{D}}{\mathrm{g}}\right)^{\frac{1}{2}}
$$

Where $\mu$ is equal to the characteristic strength of TCFP bearing divided by the normal load supported isolation devices. D represents design displacement capacity. A preliminary estimation of diameter of concave plate, $D_{c}$, is selected to be $1778 \mathrm{~mm}$ (typically). Diameter of concave plate could be selected bigger or smaller. Selected diameter could be changed depends on desirable friction of coefficient and axial load supported by bearing. Piers of bridge support different axial load values and two type isolators should be designed. In this study, TCFP bearing is designed according to axial loads which are $W_{1}=9094 \mathrm{kN}$ and $W_{2}=12122 \mathrm{kN}$. Other concave plates, $D_{S}$ and $D_{R}$, are selected to be $584 \mathrm{~mm}$ and $457 \mathrm{~mm}$, respectively. Heights of sliders $\left(h_{1}+h_{4}, h_{2}+h_{3}\right)$ are selected as $406 \mathrm{~mm}$ and $305 \mathrm{~mm}$, respectively. Diameter of concave surfaces 1 and 2 are selected as $3962 \mathrm{~mm}$ and $1555 \mathrm{~mm}$, respectively. The height of plates 1 and 2 are selected as $203 \mathrm{~mm}$ and $152 \mathrm{~mm}$, respectively. The displacement capacity of $i^{\text {th }}$ surface is determined by Equation (2).

$$
\mathrm{d}_{\mathrm{i}}^{*}=\mathrm{d}_{\mathrm{i}} \frac{\mathrm{R}_{\mathrm{effi}}}{\mathrm{R}_{\mathrm{i}}}
$$

where $d_{i}{ }^{*}$ is actual displacement capacity of $i^{\text {th }}$ surface, $d_{i}$ is displacement capacity of $i^{\text {th }}$ surface. The actual displacement capacity of surface 1 and 4 is calculated as $566 \mathrm{~mm}$. The actual displacement capacity of surface 2 and 3 is calculated as $57 \mathrm{~mm}$. Bearing pressure is different on surfaces 1-4 and 2-3. Pressure of each of the surface is calculated by Equation (3) .

$$
\mathrm{P}=\frac{\mathrm{W}}{\pi(\mathrm{D} / 2)^{2}}
$$

In which $P$ is bearing pressure, $W$ is the vertical compressive load on the bearing and $D$ is size of surface whose pressure is calculated. Tri-cycle coefficient of friction is determined by Equation (4).

$$
\begin{aligned}
& \mathrm{k}_{3 \mathrm{ccf}}=0.122-0.01 \mathrm{P} \\
& \text { One-cycle coefficient of friction is determined by Equation (5). } \\
& \mathrm{k}_{1 \mathrm{ccf}}=1.2 * \mathrm{k}_{1 \mathrm{bcf}}
\end{aligned}
$$
Equation (6).

$$
\mathrm{k}_{\mathrm{ubcf}}=\lambda_{\max } * \mathrm{k}_{1 \mathrm{ccf}}
$$

$\lambda$ max results from aging, contamination and travel. It is selected as 1.386. The frictional calculated by Equation (7).

$$
\mu_{\mathrm{ib}}=\frac{2 \mathrm{~W}_{1} \mu_{1 \mathrm{i}}+2 \mathrm{~W}_{2} \mu_{2 \mathrm{i}}}{2 \mathrm{~W}_{1}+2 \mathrm{~W}_{2}}
$$
properties of combined system are

Where $\mu_{i b}$ is coefficient of friction of $i^{\text {th }}$ surface in the combined situation. $\mu_{1 i}$ and $\mu_{2 i}$ are coefficient of friction of $i^{\text {th }}$ surface in case vertical load is $W_{1}$ and $W_{2}$, respectively. The properties of two different load cases are given in Table 1. 
Yurdakul, M. and Ateş, S.., Engineering Sciences (NWSAENS), 1A0415, 2018; 13(3): 229-246.

\begin{tabular}{l}
\hline \hline \multicolumn{1}{|c|}{ Table 1. Properties of TCFP and Combined System } \\
\begin{tabular}{|l|c|c|c|}
\hline \multicolumn{1}{|c|}{} & $W_{1}=9094 \mathrm{kN}$ & $W_{2}=12122 \mathrm{kN}$ & Combined system $(\mathrm{kN})$ \\
\hline$R_{\text {eff }}=\mathrm{R}_{\text {eff4 }}(\mathrm{mm})$ & 3759 & 3759 & 3759 \\
\hline $\mathrm{R}_{\mathrm{eff2}}=\mathrm{R}_{\mathrm{eff3}}(\mathrm{mm})$ & 1403 & 1403 & 1403 \\
\hline $\mathrm{d}_{1}{ }^{*}=\mathrm{d}_{4}{ }^{*}(\mathrm{~mm})$ & 566 & 566 & 566 \\
\hline $\mathrm{d}_{2}{ }^{*}=\mathrm{d}_{3}{ }^{*}(\mathrm{~mm})$ & 58 & 58 & 0.048 \\
\hline$\mu_{1}=\mu_{4}$ Lower Bound & 0.058 & 0.041 & 0.021 \\
\hline$\mu_{2}=\mu_{3}$ Lower Bound & 0.037 & 0.010 & 0.038 \\
\hline$\mu$ Lower Bound & 0.050 & 0.030 & 0.081 \\
\hline$\mu_{1}=\mu_{4}$ Upper Bound & 0.096 & 0.069 & 0.035 \\
\hline$\mu_{2}=\mu_{3}$ Upper Bound & 0.061 & 0.016 & 0.064 \\
\hline$\mu$ Upper Bound & 0.083 & 0.049 & \\
\hline
\end{tabular}
\end{tabular}

In Table $1, \mu$ is the value obtained by dividing force by normal load when displacement is zero and is shown in Figure 2. $\mu$ value is obtained by the Equation (8).

$$
\mu=\mu_{1}-\left(\mu_{1}-\mu_{2}\right) \frac{R_{\text {eff } 2}}{R_{\text {eff } 1}}
$$

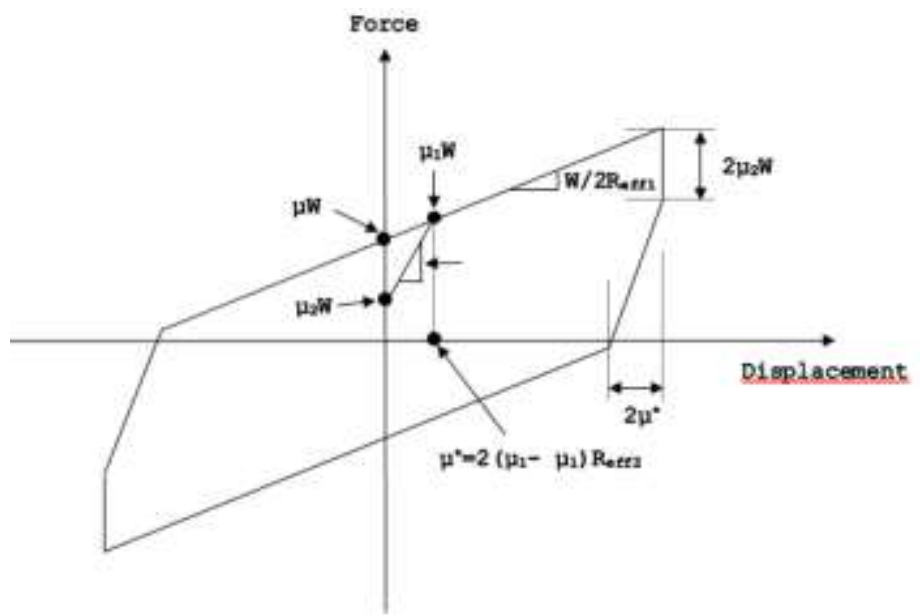

Figure 2. Force-Displacement Relationship of TCFP bearing

The effective coefficient of friction of the TCFP bearing system is obtained by the following Equation (9).

$$
\mu_{\mathrm{e}}=\frac{\mu_{1}\left(\mathrm{R}_{1}-\mathrm{h}_{1}\right)+\mu_{2}\left(\mathrm{R}_{2-} \mathrm{h}_{2}\right)+\mu_{3}\left(\mathrm{R}_{3}-\mathrm{h}_{3}\right)+\mu_{4}\left(\mathrm{R}_{4-}-\mathrm{h}_{4}\right)}{\mathrm{R}_{1}+\mathrm{R}_{2}+\mathrm{R}_{3}+\mathrm{R}_{4}-\mathrm{h}_{1}-\mathrm{h}_{2}-\mathrm{h}_{3}-\mathrm{h}_{4}}
$$

Seismic device as the TCFP bearing has an important role to changing natural period of the supported structure. The natural period of the vibration is given by Equation (9).

$$
\mathrm{T}=2 \pi \sqrt{\frac{\mathrm{R}}{\mathrm{g}}}
$$

where $R$ is the radius of spherical concave surface and $g$ is the acceleration of gravity. The force-displacement relationship of the SCFP bearings in any direction may be given by the Equation (10) .

$$
\mathrm{F}=\frac{\mathrm{W}}{\mathrm{R}} \mathrm{V}_{\mathrm{b}}+\mu_{\mathrm{s}} \mathrm{WSign}\left(\dot{\mathrm{V}}_{\mathrm{b}}\right)
$$

where $W, R, V_{b}, \mu_{s}$, and $\dot{V}_{b}$ are the total weight carried by the SCFP, the radius of the spherical concave surface, the sliding displacement, the coefficient friction on the sliding surface and the sliding velocity, respectively. Sign is the signum function. The lateral restoring stiffness of the SCFP is given by the Equation (11).

$$
\mathrm{k}_{\mathrm{b}}=\frac{\mathrm{W}}{\mathrm{R}}
$$


It is also shown in Equation (11) that the stiffness of the pendulum depends on the weight carried by the bearing. Equivalent stiffness of the bearing is given by Equation (12) [22].

$$
\mathrm{k}_{\mathrm{eş}}=\frac{\mathrm{W}}{\mathrm{R}_{\mathrm{eff}}}+\frac{\mu_{\mathrm{e}} \mathrm{W}}{\left(\mathrm{V}_{\mathrm{b}}\right)_{\max }}
$$

Where $\left(V_{b}\right)_{\max }$ is maximum displacement capacity of the SCFP, $f_{\min }$ is minimum mobilized coefficient of friction. The stiffness of the FPS system before it sliding is given by Equation (13).

$$
\mathrm{k}_{\mathrm{e}}=\frac{\mathrm{f}_{\min } \mathrm{W}}{\mathrm{V}_{\mathrm{b}}}
$$

Where $V_{b}$ is displacement of bearing. The single mode method of analysis, spectrum analysis and time history analysis are used to determine displacement capacity of the TCFP bearing [21]. The spectrum and the time history analyses are performed in SAP2000 [23]. Results of these analyses are compared each other and displacement capacity of TCFP bearing is determined. Single mode method of analysis is performed in the design earthquake (DE). Analyses procedure of seismic isolation system for upper bound by using bilinear hysteretic model is given Figure 3. In this Figure, $K_{d}, Q_{d}$ and $Y$ are represented postelastic stiffness, characteristic strength and yield displacement, respectively. Post-elastic stiffness is given by Equation (14).

$$
\mathrm{k}_{\mathrm{d}}=\frac{\mathrm{W}}{2 \mathrm{R}_{\mathrm{eff} 1}}
$$

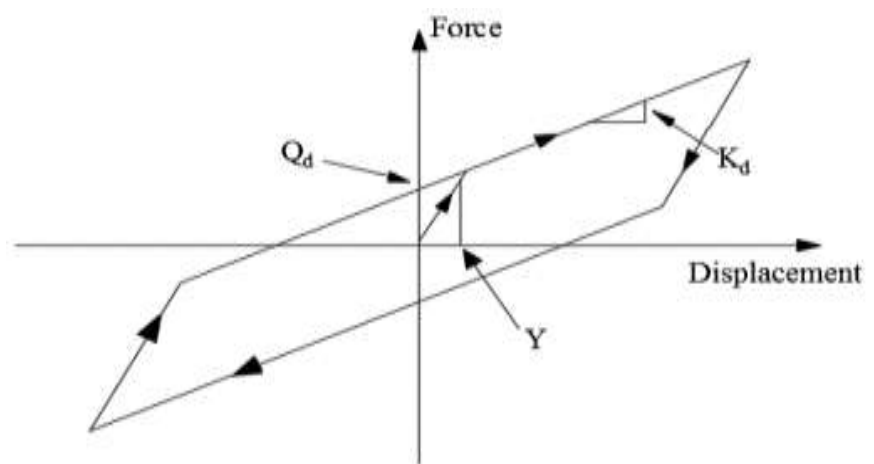

Figure 3. Force-Displacement Relationship

The post-elastic stiffness is calculated as $10441 \mathrm{kN} / \mathrm{m}$ by means of Equation (14). The Characteristic strength is given by Equation (15) .

$\mathrm{Q}_{\mathrm{d}}=\mu \mathrm{W}$

where $\mu$ is coefficient tof friction of combined system (weighted average system). Different axial loads which supported by different isolator is considered in a single isolator in combined system. The characteristic strength is calculated as $2705 \mathrm{kN}$ by means of Equation (15). The yield displacement is given by Equation (16) .

$\mathrm{Y}=\left(\mu_{1}-\mu_{2}\right) \mathrm{R}_{\mathrm{eff} 2}$

The yield displacement is calculated as $0,0634 \mathrm{~m}$ by means of Equation (16). Displacement of the TCFP bearing could be estimated at single mode analysis and shown in following steps.

- The displacement capacity of TCFP bearing is selected as $0.278 \mathrm{~m}$

- The effective stiffness is given by Equation (17) and calculated as $15375 \mathrm{kN} / \mathrm{m}$.

$$
\mathrm{K}_{\mathrm{eff}}=\mathrm{k}_{\mathrm{d}}+\frac{\mathrm{Q}_{\mathrm{d}}}{\mathrm{D}_{\mathrm{D}}}
$$

- The effective period is given by Equation (18) and calculated as $3 \mathrm{~s}$.

$$
\mathrm{T}_{\mathrm{eff}}=\sqrt{\frac{\mathrm{W}}{\mathrm{gK}_{\mathrm{eff}}}}
$$


- The effective damping is given by Equation (19) and calculated as 0.311. But effective damping should be 0.3 to ensure recentering of bearing at DE.

$\beta_{\text {eff }}=\frac{E}{2 \pi K_{e f f} D_{D}^{2}}=\frac{4 \mu\left(D_{D}-Y\right)}{2 \pi K_{e f f} D_{D}^{2}}$

- Damping reduction factor is given by Equation (20) and calculated as 1.712 .

$\mathrm{B}=\left(\frac{\beta_{\text {eff }}}{0.05}\right)^{0.3}$

The spectral acceleration of response spectrum of PUL164 component of 1971 San Fernando earthquake for 5\% damping is used. The corresponding value in the effective period in the response spectrum is $2.084 \mathrm{~m} / \mathrm{s}^{2}$. The design displacement is calculated as $0.272 \mathrm{~m}$ and given by Equation (21).

$$
\mathrm{S}_{\mathrm{D}}=\frac{\mathrm{S}_{\mathrm{a}} \mathrm{T}_{\mathrm{eff}}{ }^{2}}{4 \pi^{2} \mathrm{~B}}
$$

In a similar way, the displacement of TCFP bearing was estimated using the bilinear hysteretic model of the isolated system according to the lower bound condition. Analyses results obtained by using single mode method of analysis for characteristics of the isolator used for the lower and upper bound conditions are given in Table 2.

Table 2 Displacement and damping capacities of the TCFP bearings using single mode method

\begin{tabular}{|l|c|c|c|c|}
\hline \multirow{2}{*}{ Parameters } & \multicolumn{2}{|c|}{ Design Earthquake (DE) } & \multicolumn{2}{c|}{$\begin{array}{c}\text { Maximum Considered Earthquake } \\
\text { (MCE) }\end{array}$} \\
\cline { 2 - 5 } & Lower Bound & Upper Bound & Lower Bound & Upper Bound \\
\hline Displacement $(\mathrm{mm})$ & 284 & 278 & 578 & 565 \\
\hline Effective Damping & $28 \%$ & $30 \%$ & $28 \%$ & $30 \%$ \\
\hline
\end{tabular}

The response spectrum analysis is performed using SAP2000 commercial software. Each isolator device is represented horizontal stiffness based on single mode method of analysis. To obtain a response spectrum according as a damping ratio differs from original response spectrum and Equation (22) [24] was used.

$$
\mathrm{B}=\frac{4}{5.6-\ln \left(100 \beta_{\mathrm{eff}}\right)}
$$

Where $\beta_{\text {eff }}$ is effective damping ratio, $B$ is the coefficient that multiplies the 5\% damped spectrum curve. The values, $\beta_{\text {eff }}$ and $\mathrm{T}_{\text {eff }}$, are used obtained from single mode method are used. $\beta_{\text {eff }}$ is calculated as $28 \%$ and 30\% for lower and upper bound, respectively. B is calculated as 1.759 and 1.819 for lower and upper bound, respectively. Changed spectrum ration is only used isolation mode. In other words, in periods greater than 0.8 Teff, the ordinate of the 5\% damped spectrum is reduced by $B$ value. The reduced spectrum cure for lower and upper bound conditions are shown in Figure 4. The displacement of the TCFP bearing obtained from analysis using response spectrum of PUL164 component of 1971 San Fernando earthquake for 5\% damping is calculated as $314 \mathrm{~mm}$. The nonlinear time history method is used for system stability control and evaluation of the performance of structural elements as well as for estimating the maximum displacement of the isolator. PUL164 component of 1971 San Fernando earthquake is used in time history analysis. Analyses results show that the maximum displacement of isolator reaches to $400 \mathrm{~mm}$. The results of single mode method of analysis, response spectrum and time history analysis are compared to determine displacement capacity of TCFP bearing [21]. Because of comparison is indicated that maximum displacement of the isolator is $578 \mathrm{~mm}$. Because of this value is smaller than the maximum 
displacement capacity of the selected isolator, the dimensions of the isolator are enough.
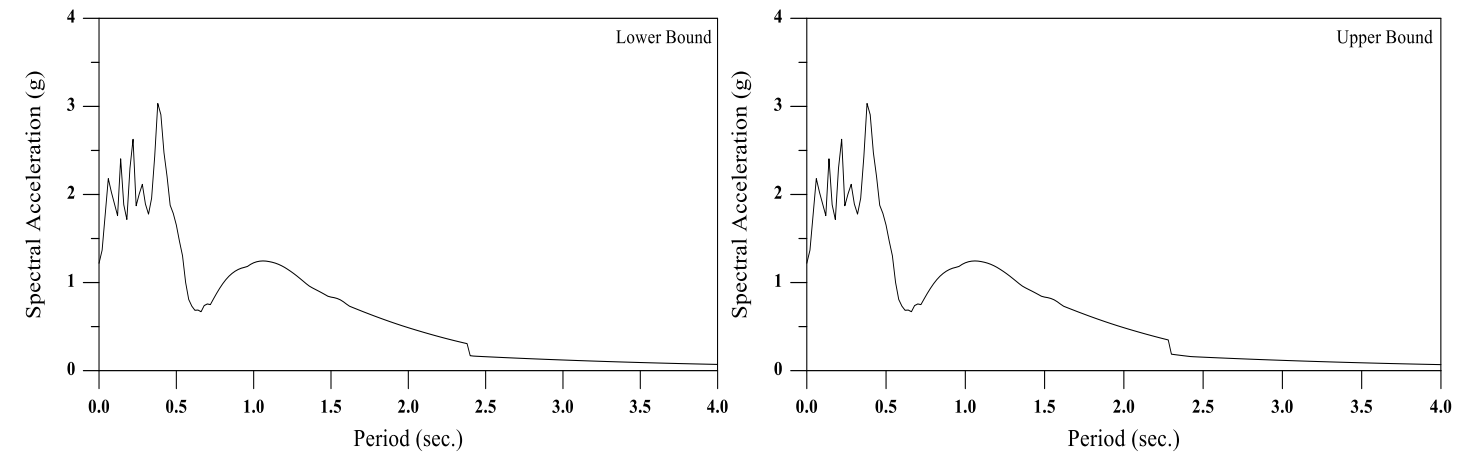

Figure 4. Reduced Response Spectra (23) .

The variance of the $i$ th total response is given by Equation

$$
\sigma_{\mathrm{z}_{\mathrm{i}}}^{2}=\sigma_{\mathrm{zi}}^{2 \mathrm{qs}}+\sigma_{\mathrm{zi}}^{2 \mathrm{~d}}+2 \operatorname{Cov}\left(\mathrm{z}_{\mathrm{i}}^{\mathrm{qs}}, \mathrm{z}_{\mathrm{i}}^{\mathrm{d}}\right)
$$

Where $\sigma_{\mathrm{zi}}^{2 \mathrm{qs}}$ is the variance of the $i$ th quasi-static response component, $\sigma_{z i}^{2}$ is the variance of the $i$ th dynamic response component and $\operatorname{Cov}\left(z_{i}^{\mathrm{qs}}, \mathrm{z}_{\mathrm{i}}^{\mathrm{d}}\right)$ is the covariance between the $i$ th quasi-static and dynamic components. The variance of the $i$ th quasi-static component can be written as Equation (24).

$$
\sigma_{\mathrm{zi}}^{2 \mathrm{qs}}=\int_{-\infty}^{\infty} \mathrm{S}_{\mathrm{z}_{\mathrm{i}}}^{\mathrm{qs}}(\omega) \mathrm{d} \omega=\sum_{\mathrm{l}=1}^{\mathrm{r}} \quad \sum_{\mathrm{l}=1}^{\mathrm{r}} \mathrm{A}_{\mathrm{il}} A_{\mathrm{im}} \int_{-\infty}^{\infty} \frac{1}{\omega^{4}} \mathrm{~S}_{\ddot{\mathrm{v}}_{\mathrm{g}}} \ddot{\mathrm{v}}_{\mathrm{gm}}(\omega) \mathrm{d} \omega
$$

Where $S_{\mathrm{z}_{\mathrm{i}}}^{\mathrm{qs}}(\omega)$ is the $i$ th quasi-static component of the spectral density function of the structural response, $r$ is the number of restrained degrees of freedom, $S_{\ddot{v}_{g_{l}} \ddot{v}_{g_{m}}}(\omega)$ is the cross-spectral density function of accelerations between supports 1 and $m, A_{i l}$ and $A_{i m}$ are equal to static displacements for unit displacements appointed to each support. The variance of the $i$ th dynamic response component may be given in Equation (25).

$$
\begin{aligned}
& \sigma_{\mathrm{zi}}^{2 \mathrm{qs}}=\int_{-\infty}^{\infty} \mathrm{S}_{\mathrm{zi}}^{\mathrm{qs}}(\omega) \mathrm{d} \omega \\
& =\sum_{\mathrm{j}=1}^{\mathrm{n}} \sum_{\mathrm{k}=1}^{\mathrm{n}} \sum_{\mathrm{l}=1}^{\mathrm{r}} \sum_{\mathrm{m}=1}^{\mathrm{r}} \Psi_{\mathrm{ij}} \Psi_{\mathrm{ik}} \Gamma_{\mathrm{lj}} \Gamma_{\mathrm{mk}} \\
& \times \int_{-\infty}^{\infty} \mathrm{H}_{\mathrm{j}}(-\omega) \mathrm{H}_{\mathrm{k}}(\omega) \mathrm{S}_{\ddot{\mathrm{v}}_{\mathrm{g}}} \ddot{\mathrm{v}}_{\mathrm{gm}}(\omega) \mathrm{d} \omega
\end{aligned}
$$

Where, $\sigma_{z_{i}}^{d}$ is the $i$ th dynamic component of the spectral density function of the structural response, $\mathrm{n}$ is the number of degrees of freedom, $\Psi$ is the eigenvectors, $\Gamma$ is the modal participation factor and $\mathrm{H}(\omega)$ is the frequency response function. The mean of maximum value and its standard deviation are most important parameters in stochastic analysis. The maximum value can be given in Equation (26) [25 and 26].

$$
\mu=\mathrm{p} \sigma_{\mathrm{z}}
$$

The standard deviation of the mean of the maximum value is given in Equation (27) [27-28].

$$
\sigma=q \sigma_{\mathrm{z}}
$$

Where $q$ and $p$ are peak factors which are zero-crossing rate and functions of the time of the motion, respectively [27].

Because of the complex structure of the earth, earthquake ground motions do not be same at support point of long span structure such as highway bridge. This occurs by considering that travelling with finite velocity, coherency loss due to reflections-refractions and difference of local soil conditions at the support points. This variation gives rise to internal forces because of quasi-static displacement. In normally, quasi-static displacements do not produce internal forces in 
the case of uniform ground motion. Therefore, spatially varying ground motion should be considered while analyzing large structures. Spatially varying earthquake ground motion model includes incoherency, wave-passage and site-response effects. The incoherency effect results from reflections and refractions of seismic waves through to the soil during their propagation. The wave passage effect results from differences in the arrival times of waves at support points. The site response effect results from differences in local soil conditions at the support point. Finite velocities of $100 \mathrm{~m} / \mathrm{s}, 200 \mathrm{~m} / \mathrm{s}$ and $400 \mathrm{~m} / \mathrm{s}$ are taken into account in the stochastic analyses. In addition to this analyses are conducted under uniform ground motion to compare results.

\section{ANALYTICAL STUDY}

Two dimensional analytical model is selected as a numerical example to investigate the stochastic response of nonisolated and isolated bridge with TCFP bearing under spatially varying ground motion. The selected highway bridge and its analytical model are shown in Figure 5. The properties of the bridge are given in Table 3. The stochastic analyses of nonisolated and isolated bridge with TCFP are performed for spatially varying earthquake ground motion by considered the wave passage effect. The bridge model subjected to spatially varying ground motions in the horizontal direction.

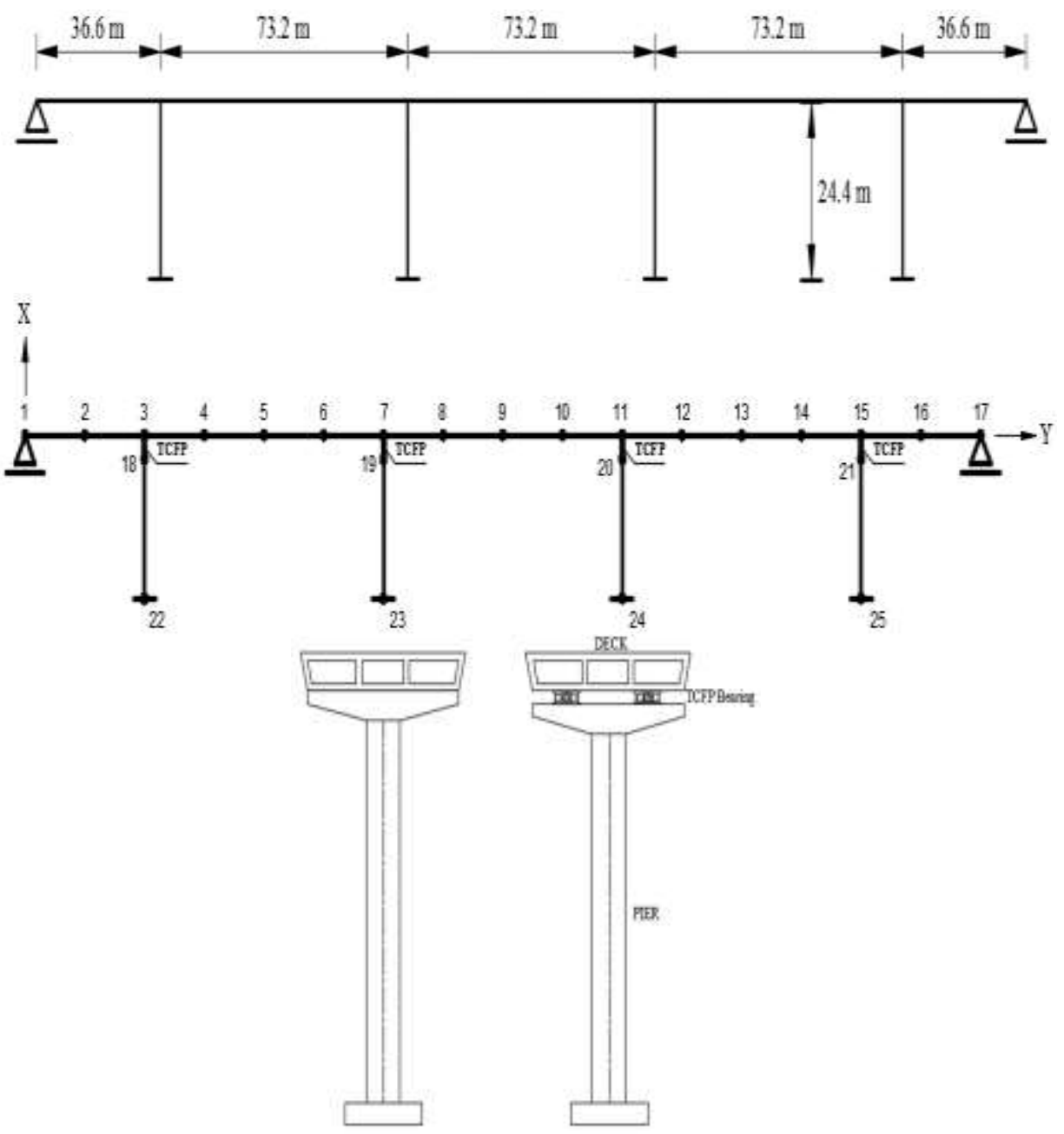

Figure 5. Selected highway bridge model and its two dimensional analytical model 
The stochastic analysis of spatially varying ground motion is performed with computer code SVEM by Dumanoğlu and Soyluk [29]. However, computer code program called SVEM has not been performed a stochastic analysis of spatially varying ground motion of an isolated structure with TCFP by now. Ates et al. [30] carried out a stochastic analysis an isolated structure with SCFP bearing. Considering the change components of the earthquake motion, behavior of TCFP bearing is attached in the program and stochastic analysis of spatially varying ground motion includes wave passage effect is performed.

Table 3. Properties of the bridge

\begin{tabular}{|l|c|c|}
\hline Properties & Deck & Pier \\
\hline Young' Modules $\left(\mathrm{kN} / \mathrm{m}^{2}\right)$ & 32000000 & 32000000 \\
\hline Cross Section $\left(\mathrm{m}^{2}\right)$ & 6.9 & 4.9 \\
\hline Moment of Inertia in the case of Vertical Bending $\left(\mathrm{m}^{4}\right)$ & 4.2 & 1.92 \\
\hline Moment of Inertia in the case of Lateral Bending $\left(\mathrm{m}^{4}\right)$ & 79.18 & 1.92 \\
\hline Torsional Moment & 14.18 & 3.84 \\
\hline Poisson's Ratio & 0.25 & 0.25 \\
\hline Unit Weight (kN/m $\left.{ }^{3}\right)$ & 25 & 25 \\
\hline Unit Length Weight (kN/m) & 165.60 & 122.75 \\
\hline
\end{tabular}

\section{RESULTS AND DISCUSSION}

Stochastic analyses of nonisolated and isolated highway bridge with TCFP under spatially varying ground motions including wavepassage effect are performed in this study. The nonisolated and isolated highway bridge model subjected to spatially varying ground motions in the horizontal direction. This horizontal input is assumed to travel with finite velocities of $100 \mathrm{~m} / \mathrm{s}, 200 \mathrm{~m} / \mathrm{s}$ and $400 \mathrm{~m} / \mathrm{s}$. Also, the results of these stochastic analyses are compared with the results of infinite velocity.

Quasi-static, dynamic, total components of internal forces and displacements of nonisolated and isolated bridges are investigated for different velocities. Means of maximum quasi-static, dynamic and total axial forces of the nonisolated and isolated bridge deck compared for four different velocities are presented Figure 6. The bridge supported on homogenous soft soil. The use of the TCFP bearing system may be reduced the maximum values of the quasi-static, dynamic and total axial forces of the bridge deck by 89\%, 74\% and 96\%, respectively. While the values of quasi-static and total axial forces increase the middle of the bridge length, these forces decrease towards abutment. When the wave propagation velocity is $100 \mathrm{~m} / \mathrm{s}$, the maximum total axial force value on the nonisolated bridge deck is 58\%, 145\%, 516\% greater than the wave propagation velocity of $200 \mathrm{~m} / \mathrm{s}, 400 \mathrm{~m} / \mathrm{s}$ and infinite velocity, respectively. When the wave propagation velocity is $100 \mathrm{~m} / \mathrm{s}$, the maximum total axial force value on the isolated bridge deck is $38 \%, 77 \%$, 159\% greater than the wave propagation velocity of $200 \mathrm{~m} / \mathrm{s}$, $400 \mathrm{~m} / \mathrm{s}$ and infinite velocity, respectively. 
Yurdakul, M. and Ates, S., Engineering Sciences (NWSAENS), 1A0415, 2018; 13(3): 229-246.
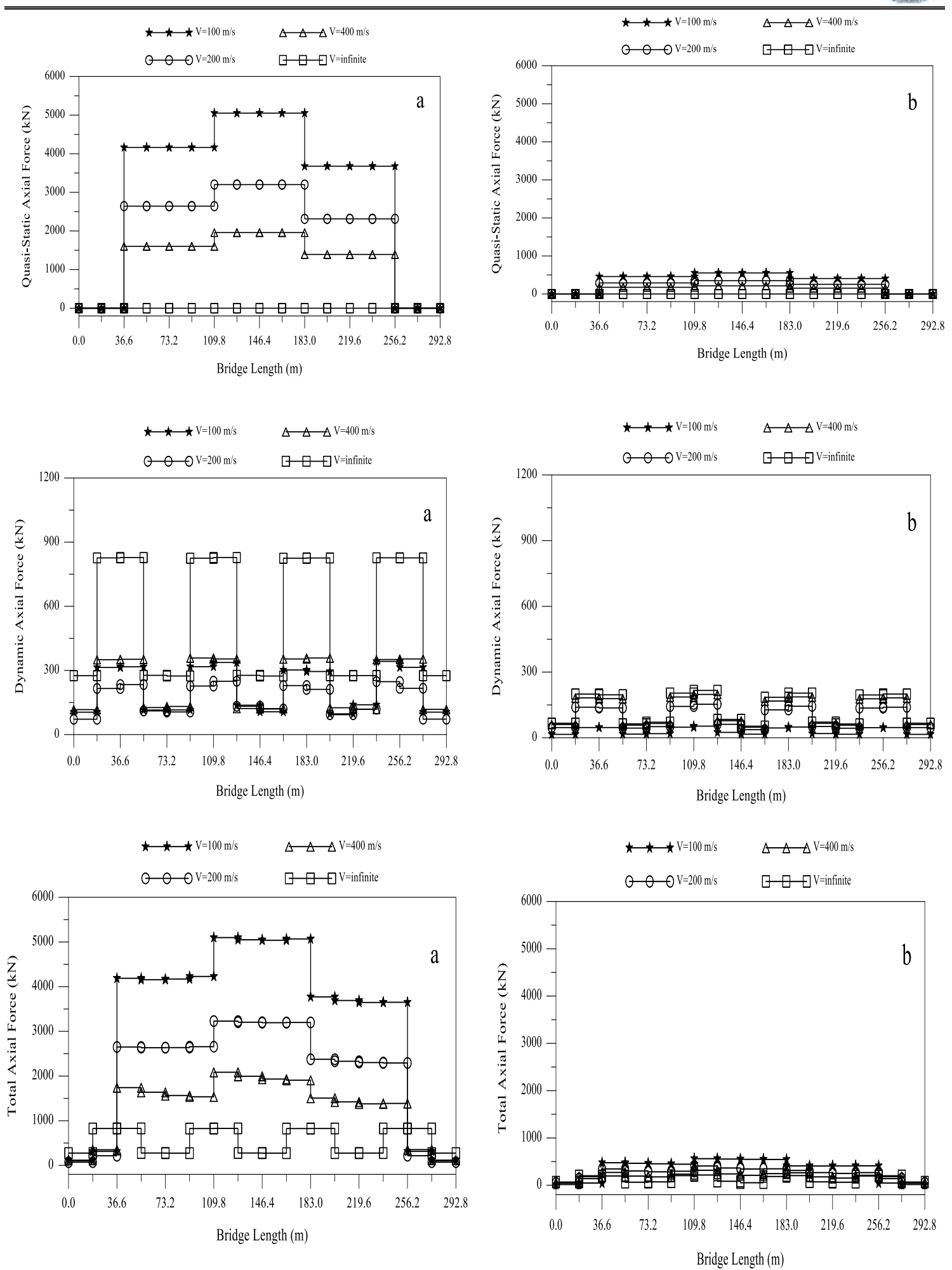

Figure 6. Means of maximum quasi-static, dynamic and total axial forces of the nonisolated (a) and isolated (b)bridge deck 
Means of maximum quasi-static, dynamic and total shear forces of the nonisolated and isolated bridge deck compared for four different velocities are presented Figure 7. The bridge supported on homogenous soft soil. The use of the TCFP bearing system may be reduced the maximum values of the quasi-static, dynamic and total shear forces of the bridge deck by $96 \%, 72 \%$ and $86 \%$, respectively. When the wave propagation velocity is $100 \mathrm{~m} / \mathrm{s}$, the maximum total shear force value on the nonisolated bridge deck is 58\%, 107\%, 94\% greater than the wave propagation velocity of $200 \mathrm{~m} / \mathrm{s}, 400 \mathrm{~m} / \mathrm{s}$ and infinite velocity, respectively. When the wave propagation velocity is infinite, the maximum total shear force value on the isolated bridge deck is $120 \%$, $30 \%$, 7\% greater than the wave propagation velocity of $100 \mathrm{~m} / \mathrm{s}, 200 \mathrm{~m} / \mathrm{s}$ and $400 \mathrm{~m} / \mathrm{s}$ velocity, respectively.
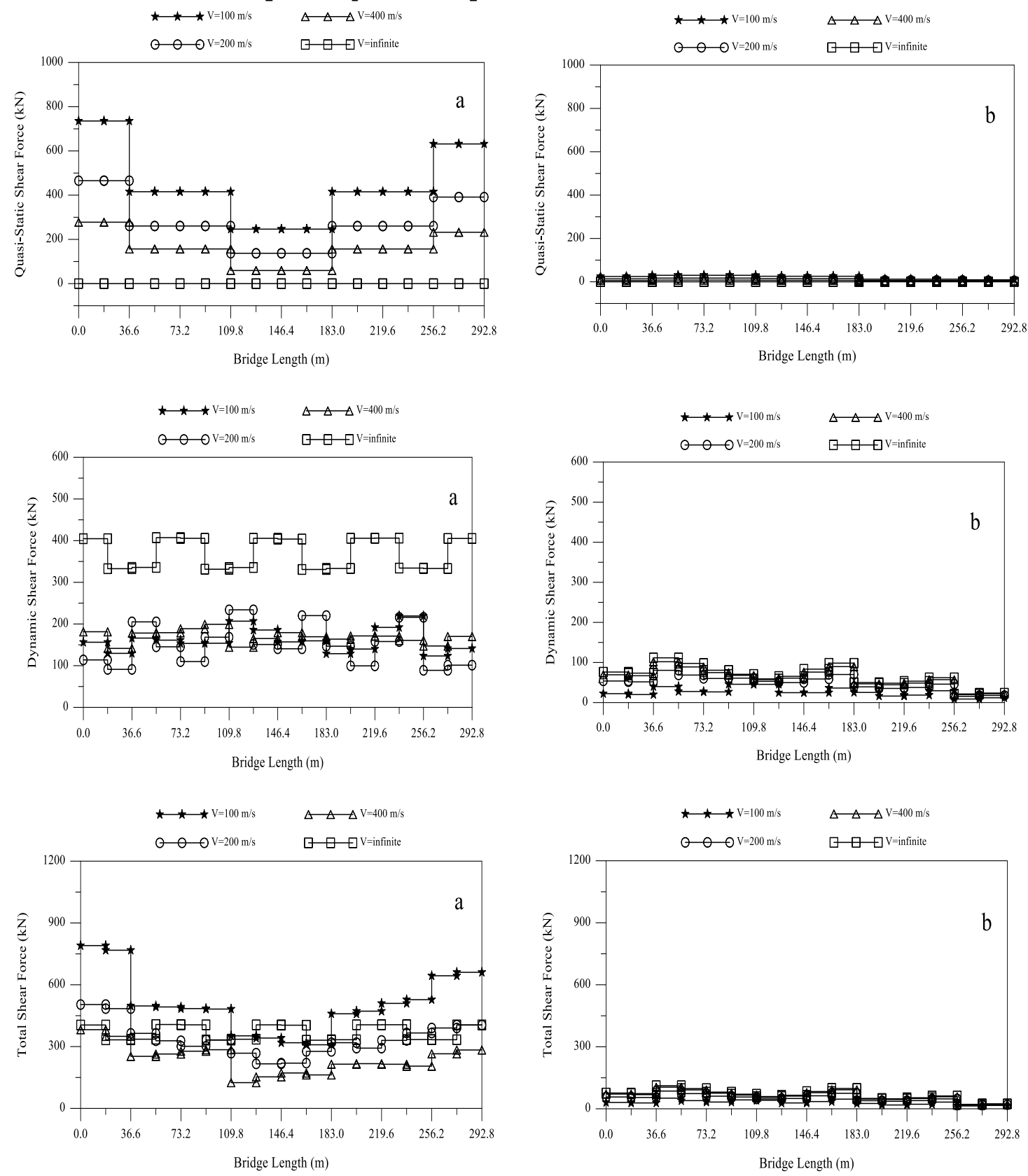

Figure 7. Means of maximum quasi-static, dynamic and total shear forces of the nonisolated (a) and isolated (b) bridge deck 
Means of maximum quasi-static, dynamic and total bending moment of the nonisolated and isolated bridge deck compared for four different velocities are presented Figure 8. The bridge supported on homogenous soft soil. The use of the TCFP bearing system may be reduced the maximum values of the quasi-static, dynamic and total bending moment of the bridge deck by 95\%, 91\% and 90\%, respectively. When the wave propagation velocity is $100 \mathrm{~m} / \mathrm{s}$, the maximum total bending moment value on the nonisolated bridge deck is 58\%, 113\%, 111\% greater than the wave propagation velocity of $200 \mathrm{~m} / \mathrm{s}, 400 \mathrm{~m} / \mathrm{s}$ and infinite velocity, respectively. When the wave propagation velocity is infinite, the maximum total bending moment value on the isolated bridge deck is 155\%, 33\%, 7\% greater than the wave propagation velocity of $100 \mathrm{~m} / \mathrm{s}, 200 \mathrm{~m} / \mathrm{s}$ and $400 \mathrm{~m} / \mathrm{s}$ velocity, respectively.
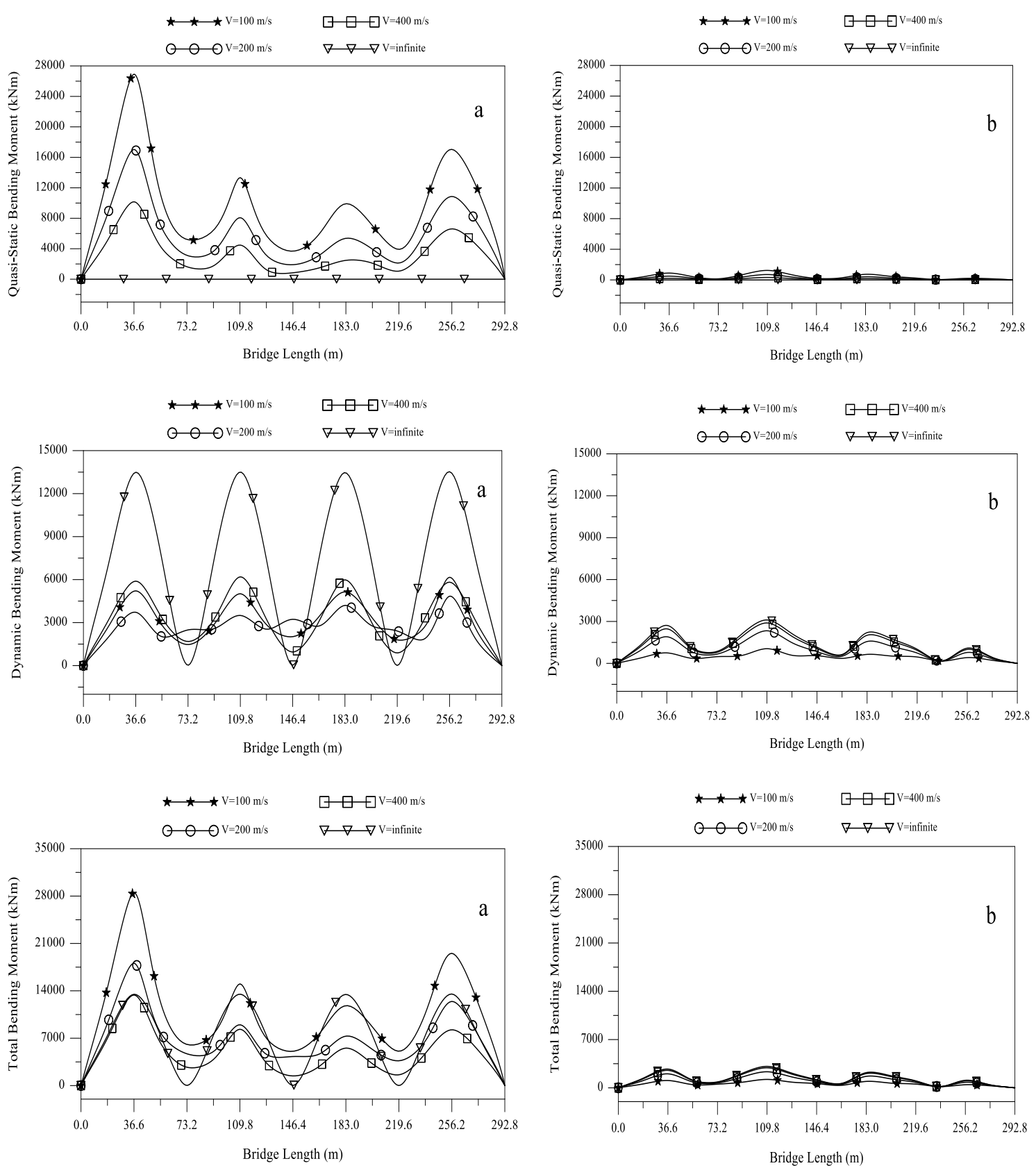

Figure 8. Means of maximum quasi-static, dynamic and total bending moment of the nonisolated (a) and isolated (b) bridge deck 
Means of maximum quasi-static, dynamic and total displacement of the nonisolated and isolated bridge deck compared for four different velocities are presented Figure 9. The bridge supported on homogenous soft soil. Mean of maximum quasi-static displacements of isolated and nonisolated bridge deck are nearly same. Using TCFP bearing system increases mean of maximum dynamic and total horizontal displacement of deck bridge are 128\% and 11\% respectively. Because the TCFP bearing is an isolation system that cause large displacement of the bridge deck, the displacements obtained in the case of base isolation are higher than those of the case of nonisolation system. This indicates that earthquake energy is damped by displacing on the friction surfaces of the TCFP bearing.
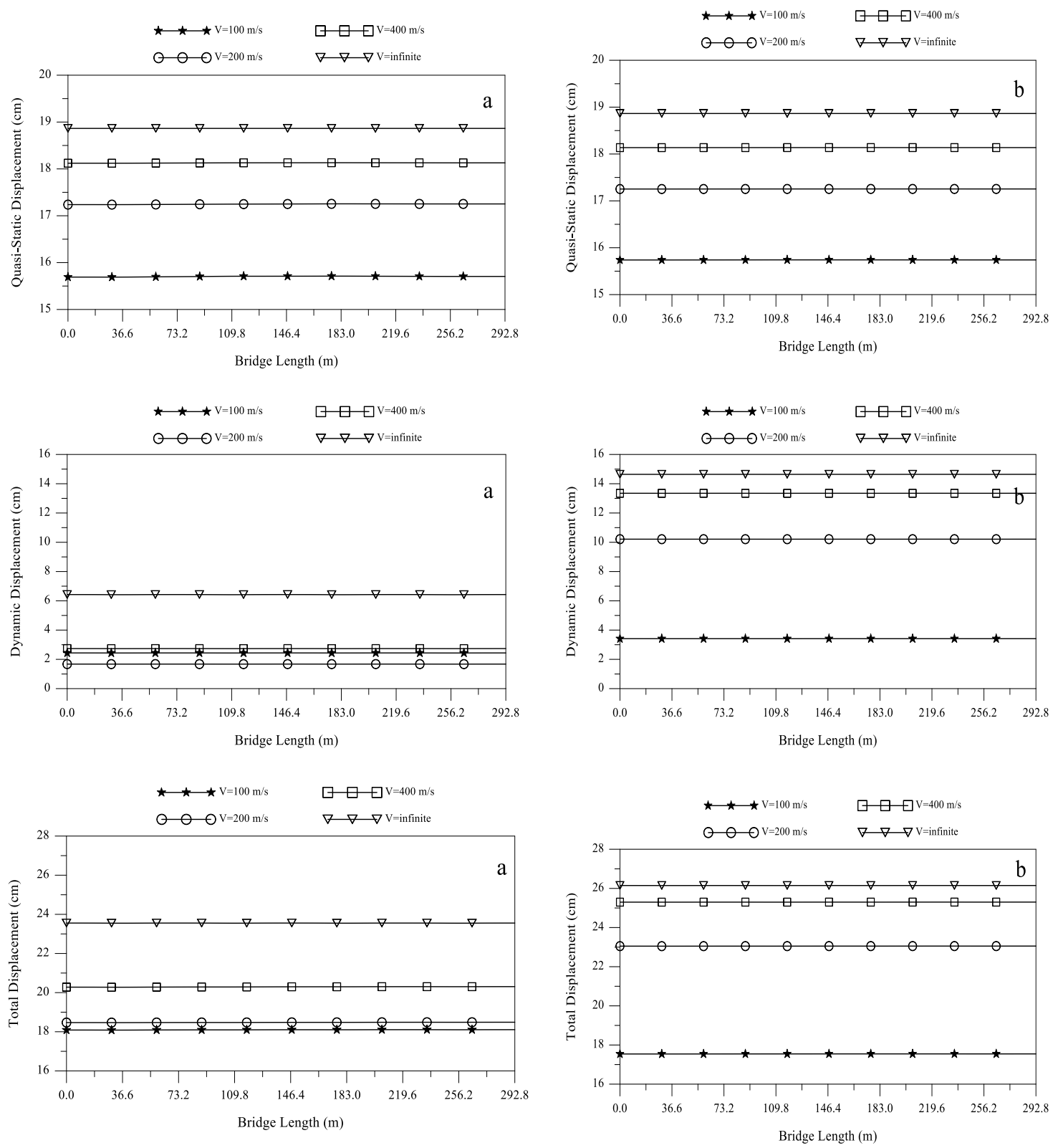

Figure 9. Means of maximum quasi-static, dynamic and total displacement of the nonisolated (a) and isolated (b) bridge deck

The infinite velocity is the most effective in the stochastic analyses. When the wave propagation velocity is infinite velocity, the 
maximum total displacement value on the nonisolated bridge deck is $30 \%, 27 \%$, $16 \%$ greater than the wave propagation velocity of $100 \mathrm{~m} / \mathrm{s}$, $200 \mathrm{~m} / \mathrm{s}$ and $400 \mathrm{~m} / \mathrm{s}$, respectively. When the wave propagation velocity is infinite, the maximum total bending moment value on the isolated bridge deck is 49\%, 13\%, 3\% greater than the wave propagation velocity of $100 \mathrm{~m} / \mathrm{s}, 200 \mathrm{~m} / \mathrm{s}$ and $400 \mathrm{~m} / \mathrm{s}$ velocity, respectively.

\section{CONLUSIONS}

In this paper, the stochastic responses of isolated and isolated bridge with TCFP bearing system were investigated. The nonisolated and isolated bridge models were subjected to spatially varying ground motions. The TCFP bearing system was designed and installed between bridge deck and pier. The wave passage effect is considered in the spatially varying ground motions. The isolated and nonisolated bridge models including wave passage effect were analysed different velocities. The horizontal input is assumed to travel across the bridge from left to right side with finite velocities of $100 \mathrm{~m} / \mathrm{s}$, $200 \mathrm{~m} / \mathrm{s}$ and $400 \mathrm{~m} / \mathrm{s}$. The results of these stochastic analyses are also compared with the results of infinite velocity. The analyses are carried out for nonisolated and isolated bridges, separately. Comparing the results of this study, the following observations can be made:

- The use of the TCFP bearing system on the isolated bridge may be average reduced the element forces of bridge deck by 86\% to 96\%.

- The means of maximum total axial forces decrease as the wave propagation velocity increases in the nonisolated and isolated bridge with TCFP bearing.

- In case of infinite velocity, the means of maximum total axial forces of nonisolated and isolated bridge deck are the least.

- The means of maximum total shear forces of nonisolated bridge deck are decreases when the speed increases.

- The means of maximum total shear forces of isolated bridge deck are increase when the speed increases.

- When the wave propagation speed is infinite, the total shear forces and bending moment of nonisolated bridge deck are over than the speed is $400 \mathrm{~m} / \mathrm{s}$, less than speed is $100 \mathrm{~m} / \mathrm{s}$ and $200 \mathrm{~m} / \mathrm{s}$.

- In case of infinite velocity, the means of maximum total shear forces and bending moment of isolated bridge deck are the highest.

- The means of maximum total bending moment of nonisolated bridge deck are decreases when the speed increases.

- The means of maximum total bending moment of isolated bridge deck are increase when the speed increases.

- The means of maximum total displacement of nonisolated and isolated bridge deck are increase when the speed increases.

- The finite velocity is the most effective at means of the maximum responses of horizontal displacement of nonisolated and isolated bridge deck.

- The finite velocity is the most effective dynamic responses of the nonisolated and isolated bridge deck.

\section{NOTICE}

This study was presented as an oral presentation at the International Conference on Advanced Engineering Technologies (ICADET) in Bayburt between 21-23 September 2017. 
Yurdakul, M. and Ateş, S. Engineering Sciences (NWSAENS), 1A0415, 2018; 13(3): 229-246.

\section{REFERENCES}

[1] Zayas, V.A., Low, S.S., Mahin, S.A., and Bozzo, L., (1989). Feasibility and Performance Studies on Improving The Earthquake Resistance of New Existing Building Using The Friction Pendulum System, In: Report No. UCB/EERC 89-09. Berkeley (CA): Earthquake Engineering and Research Center, College of Engineering, University of California.

[2] Fenz, D.M., (2008). Development, Implementation and Verification of Dynamic Analysis Models for Multi-Spherical Sliding Bearings, Technical Report MCEER-08-0018, Multidisciplinary Center for Earthquake Engineering Research, University at Buffalo, State University of New York, Buffalo, NY.

[3] Barbas, J., Matusewitch, P., and Williams, M., (2011). Comparative of Single Pendulum and Triple Pendulum Seismic Isolation Bearings on The St. Laurent Bridge, Quebec, Canada: 6th New York City Bridge Conference on Modern Techniques in Design, Inspection, Monitoring and Rehabilitation of Bridge Structures, New York City, July 25-26.

[4] Yurdakul, M., Ates, S., and Altunisik, A.C., (2014). Comparison of The Dynamic Responses of Gülburnu Highway Bridge Using Single and Triple Concave Friction Pendulums, Earthquakes and Structures, Volume:7, Issue:4, pp:511-525.

[5] Bucher, C., (2011). Optimal Friction Pendulum Systems for Seismic Isolation: Proceedings of The 8th International Conference On Structural Dynamics, Leuven, Belgium, July 04-06.

[6] Tajammolian, H., Khoshnoudian, F., Talaei, S., and Loghman, V., (2014). The Effects of Peak Ground Velocity of Near-Field Ground Motions on The Seismic Responses of Base-Isolated Structures Mounted on Friction Bearings, Earthquakes and Structures, Volume:7, Issue:6, pp:1259-1281.

[7] Loghman, V. and Khoshnoudian, F., (2015), Comparison of Seismic Behavior of Long Period SDOF Systems Mounted on Friction Isolators Under Near-Field Earthquakes, Smart Structures and Systems, Volume:16. Issue:4, pp:701-723.

[8] Harichandran, R.S. and Wang, W., (1988). Response of One-And Two-Span Beams To Spatially Varying Seismic Excitation, Report to the National Science Foundation MSU-ENGR-88-002, Michigan (MI): Department of Civil and Environmental Engineering, College of Engineering, Michigan State University.

[9] Ates, S., Soyluk, K., Dumanoglu, A.A., and Bayraktar, A., (2009). Earthquake Response of Isolated Cable-Stayed Bridges Under Spatially Varying Ground Motions, Structural Engineering and Mechanics, Volume:31, Issue:6, pp:639-662.

[10] Avanoğlu, S.E. and Soyluk, K., (2012). Investıgation of The Effect of Spatially Varying Ground Motion Components on The Dynamic Behaviour of Cable Stayed Bridges Depending on Soil Conditions, Journal of The Faculty of Engineering and Architecture of Gazi University, Volume:27, Issue:4, pp:881-889.

[11] Li, B., Bi, K., Chouw, N., Butterworth, J.W., and Hao, H., (2012). Experimental Investigation of Spatially Varying Effect of Ground Motions on Bridge Pounding, Earthquake Engineering and Structural Dynamics, volume:41, Issue:14, pp:1959-1976.

[12] Jia, H.Y., Zhang, D.Y., Zheng, S.X., Xie, W.C., and Pandey, M.D., (2013). Local Site Effects on A High-Pier Railway Bridge Under Tridirectional Spatial Excitations: Nonstationary Stochastic Analysis, Soil Dynamics and Earthquake Engineering, Volume:52, pp:55-69. 
[13] Bedon, C. and Morassi, A., (2014). Dynamic Testing and Parameter Identification of A Base-Isolated Bridge, Engineering Structures, Volume:60, pp:85-99.

[14] Bo, Z., Yuanging, W., Zhihua, C., Yongjiu, S., Yang, J., and Yihong, W., (2015). Research on the Random Seismic Response Analysis for Multi-and Large-Span Structures to Multi-Support Excitations, Earthquake Engineering and Engineering Vibration, Volume:14, Issue:3, pp:527-538.

[15] Fallahian, M., Khoshnoudian, F., and Loghman, V., (2015). Torsionally Seismic Behavior of Triple Concave Friction Pendulum Bearing, Advances in Structural Engineering, Volume:18, Issue:12, pp:2151-2166.

[16] Sayed, M.A., Go, S., Cho, S.G., and Kim, D., (2015). Seismic Responses of Base-Isolated Nuclear Power Plant Structures Considering Spatially Varying Ground Motions: Structural Engineering and Mechanics, Volume:54, Issue:1, pp::169-188.

[17] Apaydın, N.M., Bas, S., and Harmandar, E., (2016). Response of The Fatih Sultan Mehmet Suspension Bridge Under Spatially Varying Multi-Point Earthquake Excitations, Soil Dynamics and Earthquake Engineering, Volume:84, pp::44-54.

[18] Adanur, S., Altunışık, A.C., Soyluk, K., Bayraktar, A., and Dumanoğlu, A.A., (2016). Multiple-Support Seismic Response of Bosporus Suspension Bridge for Various Random Vibration Methods, Case Studies in Structural Engineering, Volume:5, pp:54-67.

[19] Specification for Buildings to be Built in Seismic Zones, (2007). Ministry of Public Works and Settlement Government of Republic of Turkey, Earthquake Research Department, http://www.deprem.gov.tr, 2007 (in Turkish).

[20] Fadi, F. and Constantinou, M.C., (2009). Evaluation of Simplified Methods of Analysis for Structures With Triple Friction Pendulum Isolators, Earthquake Engineerings and Structural Dynamics, Volume:39, Issue:1, pp:5-22.

[21] Constantinou, M.C., Kalpakidis, I., Filiatrault, A., and Ecker Lay, R.A., (2011). Lrfd-Based Analysis and Design Procedures for Bridge, Fabruary 28, Technical Rapor.

[22] Scheller, J. and Constantinou, M.C., (1999). Response History Analysis of Structures With Seismic Isolation And Energy Dissipation Systems: Verification Examples for SAP2000, Technical Report MCEER-99-0002, Buffalo.

[23] Computers and Structures Inc., (2007). SAP2000: Static and Dynamic Finite Element Analysis of Structures, Berkeley, CA, U.S.A.

[24] American Society of Civil Engineers-ASCE, (2010). Minimum Design Loads for Buildings and Other Structures, Standard ASCE/SEI 710 .

[25] Button, M.R., Der Kiureghian, A., and Wilson, E.L., (1981). STOCAL-User Information Manual, Report No UCB/SEMM-81/2, Department of Civil Engineering, University of California, Berkeley, CA.

[26] Dumanoglu, A.A. and Severn, R.T., (1990). Stochastic Response of Suspension Bridges to Earthquake Forces, Earthquake Engineering and Structural Dynamics, Volume:19, Issue:1, pp:133-152.

[27] Der Kiureghian, A. and Neuenhofer, A., (1991). A Response Spectrum Method for Multiple-Support Seismic Excitations, Report No. UCB/EERC-91/08, Earthquake Engineering Research Center, College of Engineering, University of California, Berkeley, CA.

[28] Der Kiureghian, A., (1980). Structural Response to Stationary Excitation, Journal of the Engineering Mechanics Division, Volume:106, Issue:6, pp:1195-1213. 
[29] Dumanoğlu, A.A. and Soyluk, K., (2002). SVEM, A Stochastic Structural Analysis Program for Spatially Varying Earthquake Motinos, Turkish Earthquake Foundation, TDV/KT 023-76, Istanbul.

[30] Ates, S., Dumanoglu, A.A., and Bayraktar, A., (2005). Stochastic Response of Seismically Isolated Highway Bridges With Friction Pendulum Systems to Spatially Varying Earthquake Ground Motions: Engineering Structures, Volume:27, Issue:13, pp:1843-1858. 